\title{
Competition and Market Power in Broadcasting: Where Are The Rents?
}

\author{
Paul Seabright (IDEI, University of Toulouse) \\ Helen Weeds (University of Essex)
}

25 January 2006

\section{Introduction}

This chapter considers where the scarce assets are located in the broadcasting sector and what are the lessons for public interventions to prevent the abuse of market power. It focuses on what makes broadcasting different from other sectors, and on the way in which recent technological changes such as digitisation may be changing the nature and distribution of scarcity rents.

It considers two hypotheses in particular: first, that falls in the cost of reproducing and transmitting information have greatly reduced entry barriers in broadcasting, meaning that market power is less of a concern; and secondly, that rents in broadcasting will increasingly come from control of scarce content rather than from control over means of transmission. Both hypotheses contain elements of truth but the situation is more complex than either implies on its own. The chapter goes on to look at a number of challenges for competition policy, including such issues as market definition, exclusionary practices and bundling, matters that have been brought to the fore in recent anti-trust developments. It suggests that the risks attendant on these practices may be somewhat different from those that have traditionally been emphasised, and proposes rules of thumb to help identify the circumstances under which they are most likely to lead to a consolidation of market power.

We begin with a summary of technological changes in broadcasting, and an assessment of their impact on the nature of competition in broadcasting markets.

\section{The changing nature of broadcasting}

"Digitisation" is a broad term encompassing of a number of technological changes. Replacing analogue signals with digital format economises on processing, storage and transmission capacity, reducing costs and expanding capabilities. The impact of digitisation is felt across the broadcasting industry, with the following developments:

- digital recording and production techniques;

Forthcoming as Chapter 3 of The Economic Regulation of Broadcasting Markets, edited by Paul Seabright and Jürgen von Hagen, Cambridge University Press. The authors would like to thank Mark Armstrong for helpful comments. The views expressed and any errors are those of the authors. 
- use of digital compression in transmission, alongside proliferation in transmission platforms (terrestrial, cable, satellite and broadband);

- digital set-top boxes and encryption technologies; and

- digital personal video recorders.

Digital production lowers the cost of recording and editing television content and permits major quality improvements. With video footage in digital format, scenes can be edited and modified using computer-aided imaging techniques; backgrounds can be altered easily and characters may even be created. Such modifications can be achieved more cheaply, and with better results, than using older production techniques. Moreover, digital video equipment is relatively inexpensive, assisting the growth of small, independent movie producers. Digital recording and transmission, including the use of satellite video links, improves the speed and quality of news gathering and sports reporting. Other things equal, digitisation reduces the cost of programme productionalthough in recent years greater spending on special effects and higher costs of certain content rights (e.g. popular sports) may have offset this trend.

Digital compression allows many more channels to be transmitted for a given bandwidth allocation, reducing the unit cost of transmission. With analogue technology, limited transmission capacity (resulting from the scarcity of spectrum or other transmission media) constrains the number of channels that can be broadcast. By allowing much more information to be transmitted over a given bandwidth, digital format greatly increases the number of channels that can be broadcast: digital terrestrial transmission (DTT) supports several dozen channels, while digital satellite and cable platforms can support hundreds. Alongside this development, the number of transmission platforms available to viewers has proliferated with the rollout of satellite and cable (where this did not previously exist), and the growth in broadband connections. ${ }^{1}$

With the distribution of digital set-top boxes containing decoder slots, encrypted television signals can be used, overcoming the non-excludability property of traditional broadcasting. Viewers can then be charged directly for watching television, by means of subscription or pay-per-view. Sophisticated charging schemes, such as channel bundling and tiering, may be tailored to viewer demands, boosting subscription and increasing revenues. ${ }^{2}$ With viewer charging, broadcasters show programmes that match the desires

1 In the UK, for example, terrestrial coverage is near universal, satellite is accessible to the majority of households and cable networks pass around fifty percent. If broadband becomes ubiquitous, virtually all households will have access to at least two platforms and many will have the possibility of four.

2 For literature on the use of bundling and price discrimination to reduce allocative inefficiency see Adams and Yellen (1976), McAfee, McMillan and Whinston (1989), Armstrong (1999a) and Bakos and Brynjolfsson (1999). Bundling is considered at length in section 4. 
of viewers, rather than maximising the audience available to advertisers and sponsors. Although pay-TV might not be used for all programmes - it may remain desirable for some material to be provided free-to-air - it is likely to be the dominant model for highly valued, "premium” programming such as movies and popular sports.

Digital personal video recorders (PVRs) such as TiVo and the Sky+ box give viewers far greater control over their viewing than older video recorders. As well as recording huge quantities of programming, PVRs allow the viewer to pause and rewind live TV, and to skip unwanted material such as advertising. Although uptake of PVRs is low at present, as their use becomes widespread this development has two important implications. First, viewer avoidance behaviour is likely to undermine advertising as a dominant source of revenue, increasing the trend towards pay-TV. This does not mean that advertising will disappear entirely, however: broadcasters are likely to find that viewers are prepared to watch some advertisements if these are sufficiently entertaining, or if they are sufficiently unobtrusive, as with product placement. But it will change the exclusive dependence on advertiser revenues that has been the dominant broadcasting model up to now. Secondly, greater time-shifting ability increases the degree of competition between programmes shown at different times, replacing head-to-head competition between contemporaneous channels. ${ }^{3}$

In analogue broadcasting, transmission capacity forms a major barrier to entry. Most viewers have access to a single transmission platform, which has limited capacity. The number of channels is restricted by spectrum availability, with commercial broadcasters earning large scarcity rents as programme revenues (typically from the sale of advertising airtime) far exceeding costs. Depending on national broadcasting regulation and spectrum licensing policies, rents do not always appear as excess profit: broadcasters may be required to meet costly public service obligations, implicitly funded out of spectrum rents, or rents may be extracted through licence fees levied on broadcasters for their use of spectrum. ${ }^{4}$ Moreover, if the available transmission capacity is controlled by a small number of operators (perhaps even a single broadcaster), competition will be weak. ${ }^{5}$

3 This trend is further increased when television programmes are made available for internet download.

4 For example ITV plc, the largest of the UK's commercial public service broadcasters, has estimated the cost of its public service obligations at around £250million per annum (cited in The Times, 24 June 2004). Costs are also incurred by the other public service broadcasters: the BBC, Channel 4 and Five. In addition, the UK's commercial analogue broadcasters (the channel 3 licensees, including ITV plc, and Five) collectively paid £230million in licence fees in 2004. This amount is falling however, with total licence payments expected to be around £90million in 2005, reflecting falling spectrum rents as digital competition intensifies.

5 Monopoly control of transmission platforms has given rise to detailed regulation to open up access and prevent excessive pricing, such as the EU regulatory framework for electronic communications networks and services introduced in 2003. In some countries terrestrial transmission networks are 
Exploitation may then occur upstream, where buyer power results in low prices for content producers, and downstream, where monopolisation of output markets leads to high prices and poor service to consumers (both viewers and advertisers). With digital transmission, however, spectrum constraints on the number of channels are effectively removed and scarcity rents are eliminated. Existing transmission capacity is sufficient to meet demands (at current and anticipated future levels), and there is a strong incentive to utilise spare capacity that militates against using access to transmission as a barrier to entry.

This discussion would seem to imply that following digitisation, barriers to entry are eliminated and competition concerns fall away. However, other parts of the broadcasting value chain must also be considered before such a conclusion can be drawn. In particular, it is unclear how the economics of programme production are affected by digitisation. Although film recording and processing costs are reduced, production involves a number of other inputs - and in these areas expenditure may rise. Costs may be endogenous: for example, producers can decide how much to spend on high quality locations and special effects, with more authentic sets and spectacular effects raising costs substantially. If producers compete by raising quality and spending more on special effects, total production costs may not fall by as much as would be implied by the fall in filming costs per se, and might even rise, and entry may be correspondingly reduced. ${ }^{6}$

In addition the cost of premium content rights and talents, such as popular sports events and top movie stars, is determined by economic processes that are affected by industry structure and technology. Alongside the growth in multi-channel television, the price of key broadcasting content-for example the right to televise live Premier League football matches in the UK-has increased dramatically. If rights acquisition is included in the cost of programming, total expenditure has increased significantly in these premium niches. Moreover, if key content rights are scarce, these rather than transmission capacity accrue scarcity rents and become potential sources of market power. ${ }^{7}$ If so, competition

publicly owned (though this does not necessarily imply open access), or capacity is franchised to a number of broadcasters.

$6 \quad$ Sutton (1991) develops the endogenous sunk costs paradigm, which explains the persistence of high concentration in food and beverage industries, for example. Motta and Polo (2003) apply a similar framework to consider concentration and entry in the broadcasting industry.

7 Our analysis focuses on reallocation of rents between broadcasting platforms and holders of content rights. With the advent of pay-TV, rents may also shift from viewers-who now pay directly, rather than indirectly by watching advertisements - to rights-holders, such as top-flight football leagues. Evidence on whether viewers gain or lose overall is unclear: they pay more for certain programmes but receive additional ones that were previously unavailable, and quality may also rise. Moreover, in practice wide-scale intervention in the market, such as the historic role of public broadcasters and the "listing" of major sporting events to ensure free-to-air availability, further complicates the picture. The model in the appendix draws implications for viewer welfare within the context of pay-TV. 
concerns in the industry do not fall away but simply change in their origin and nature, raising new and different issues for regulators. To assess this question, the next section addresses the economics of content creation and the impact of digitisation on this process.

\section{Content, superstars and the impact of digitisation}

If the scarcity of means of production and transmission of information is being rapidly overcome due to digitisation, what can be said of the scarcity of content? Two very different views have been expressed about the impact of digitisation on content creation. One is that content is becoming more abundant as it becomes easier to create and transmit, so that rents to scarce content are falling. The scarcity is rather on the side of viewers, listeners and readers, who are submerged in content, not all of which they want and which they are increasingly able to avoid — as a consequence of this, advertisers find it increasingly difficult to gain viewer attention. ${ }^{8}$ Furthermore, it is becoming easier for viewers with niche interests to find content that corresponds to their preferences, since falling costs of worldwide transmission mean that a film or programme can reach more easily the critical mass of viewers that makes it economically viable.

The second view is that digitisation, far from reducing rents to scarce content, is increasing them, a development attested by the rising real prices paid for such premium content as top-flight football broadcasting rights. For example, annual payments for live rights to Premier League football matches in the UK have risen from £38.3million over the period 1992-97 to £167.5million in 1997-2001 and £370million in 2001-04-almost a ten-fold increase - although annual payments under the most recent agreement, for 200407, are slightly lower at £341million and cover a larger number of matches. Relatedly, certain kinds of popular programme are growing to dominate broadcasting markets at the expense of less popular, but arguably higher-quality programmes. Hollywood and Bollywood movies are driving out arthouse movies and those in languages other than English and Hindi; Big Brother and other reality-TV shows are not only taking vast audiences but are spawning copy-cat initiatives that further reduce the variety of available programmes. Bestsellers are driving quality books off the shelves, and superstars-bland and omnipresent—are driving out mere stars.

$8 \quad$ This may increase advertisers' willingness to pay for forms of advertising that are effective in reaching a large audience, although empirically this effect, if present, is difficult to distinguish from broader trends and influences. For example, the UK Competition Commission's 2003 report on the merger of Carlton Communications and Granada, forming ITV plc, commented that ITV's share of television advertising revenue has held up relatively well as its audience share has fallen since the mid-1990s, resulting in a widening "ITV premium". Alongside this, concern has been expressed that television "impacts" are falling, especially with the growing use of PVRs (such as TiVo and Sky+), and some advertisers are abandoning television advertising in favour of other media such as the internet and mobile phones. 
Which of these two views is more accurate? The first thing to note is that they are not in fact incompatible. Indeed, it is quite possible that there are more types of content available in total than ever before, and simultaneously that viewer attention is more concentrated upon a narrow range of content types than before. For these things both to be true would require only that the attention of viewers be increasingly skewed towards a small subset of the types of available content, so that the increasing numbers of content types are available, but all except a very few of these have to share a decreasing proportion of total viewers (or, strictly speaking, of viewer time). Likewise, it is possible for the rents to some kinds of premium content to be increasing while the rents to the remaining kinds are falling: all this means is that the distribution of rents is becoming more skewed over time.

Evidence on this is patchy and hard to evaluate on a consistent basis, though this possibility seems consistent with at least the bulk of the anecdotal evidence. Robert Frank and Philip Cook describe the process in their book The Winner-Take-All Society:

"Winner-take-all markets have proliferated in part because technology has greatly extended the power and reach of the planet's most gifted performers. At the turn of the century, when the state of Iowa alone had more than 1,300 opera houses, thousands of tenors earned adequate, if modest livings performing before live audiences. Now that most music we listen to is prerecorded, however, the world's best tenor can be literally everywhere at once. And since it costs no more to stamp out compact discs from Luciano Pavarotti's master recording than from a less renowned tenor's most of us now listen to Pavarotti. Millions of us are each willing to pay a little extra to hear him rather than other singers who are only marginally less able or well known; and this explains why Pavarotti earns several millions of dollars a year even as most other tenors, many of them nearly as talented, struggle to get by.”

Can we say anything systematic about the economic mechanisms involved? Several different economic models have been developed that explain some of these developments, though there is as yet, to our knowledge, no encompassing model that can explain them all. The first and best-known model is that developed by Sherwin Rosen (1981) in "The Economics of Superstars". This is a model of vertical differentiation between producers (that is, producers are located along a continuous measure of quality or "talent", and all consumers agree as to their ranking by this measure). Both price and the amount sold at that price are functions of a producer's talent, with the more talented selling more in equilibrium even though their price is higher. Indeed, it is the fact that price and quantity sold can both be increasing in talent that gives rise to the potential skewness of revenue as a function of talent, whereby small differences in talent are 
magnified into large differences in income. For instance, if both price and quantity sold are linear, then revenue is a quadratic function of talent.

This result is due to a property of imperfect substitutability in preferences: low talent is an imperfect substitute for high talent. Thus a viewer who might wish to watch a high quality programme but finds the price too high would not be consoled by being offered three lower-quality programmes instead. Technically this is ensured by assuming a fixed cost of consuming each unit of consumption (this can be interpreted as the time that has to be devoted to watching each programme). On its own this is enough to yield skewness in revenues, though it does not by itself explain the concentration of output in the hands of a few sellers. This comes from an assumption about technology, namely that there are economies of scale in production. If the technology were one of pure public good production, with zero marginal cost, then in equilibrium only one seller would serve the entire market.

So, to capture greater realism, Rosen supposes that there are sources of positive (and increasing) marginal cost even while average costs of production fall with scale. The first source is an internal diseconomy: there are costs to the seller of producing higher output. The second is an external diseconomy: the quality of the service produced by the seller declines (as perceived by the buyer) when more units are sold. Rosen uses as an example a famous opera singer giving a concert in a football stadium: this is bound to be of lower quality than in a concert hall. This decline in quality compensates for the fact that lowquality producers are otherwise unable to produce substitutes for high-quality output. However, Rosen assumes the decline in the quality of the output with quantity is smaller when the output is of higher quality (a high-talent opera singer is less challenged by singing in the Yankee Stadium than one of lesser talent would be), so that in equilibrium low-and high-quality output substitute for each other only at greatly asymmetric levels of output. These assumptions together ensure that sellers of higher talent charge only slightly higher prices than those of lower talent, but sell much larger quantities; their greater earnings come overwhelmingly from selling larger quantities than from charging higher prices.

The model has interesting and intuitive comparative-static properties, beginning with the fact that increases in demand (or in the size of the overall market) tend to raise incomes but do so proportionately more for high-talent producers. Reductions in internal and external diseconomies tend to reduce prices, which makes consumers better off but has ambiguous effects on the incomes of sellers, these being positive if demand for the service is sufficiently elastic. However, the distribution of rents between sellers is highly sensitive to whether the reductions in internal or external economies are more important. If it is mainly internal economies, then low-talent sellers benefit and more sellers enter 
the market. If it is predominantly external economies, then high-talent sellers become even more dominant and some low-talent seller can even exit.

Applying the Rosen model to broadcasting, the fact that programmes are typically bundled into channels, and channels into larger packages, means that prices for individual programmes or genres cannot generally be observed. However, the hypothesis that the higher return to talent results much more from a quantity than from a price effect can be tested by examining relative values and audience sizes for programmes of different qualities. In the UK, both Premier League (top division) and Football League (lower divisions) football matches are broadcast live on the Sky Sports channels, and thus have the same potential audience. Under current broadcasting agreements, payments per live match are around £2.5million and £0.3million for Premier League and Football League respectively_an eight-fold difference-while viewing figures differ by a factor of between three and four. ${ }^{9}$ Thus the greater earnings of the Premier League are partly, but not entirely, accounted for by higher consumption; the implicit price paid per viewer for Premier League matches is at least double that for the lower divisions.

Moreover, as a representation of broadcasting markets the Rosen model is not entirely suitable. There are three main respects in which the fit is imperfect. First of all, the significance of both external and internal diseconomies seems negligible in broadcasting. The quality of the broadcast perceived by the ten millionth viewer is surely no lower than that perceived by the millionth viewer (so no external diseconomies), while the technical cost of broadcasting to the ten millionth is surely no higher (so no internal diseconomies). In fact, broadcasting appears to display something close to a pure public goods production technology (though it differs from the case of pure public goods by being able to exclude non-paying consumers through encryption technology). Yet, though there is striking concentration in production, it is far from being dominated by a single producer. What is the explanation?

The explanation lies in the second way in which the model fails to fit the circumstances of broadcasting. This is that consumer preferences involve a great deal of variety in tastes, covering a range of genres including news and current affairs, drama, movies, comedy, arts and sport-what industrial economists call "horizontal" rather than "vertical” product differentiation. Technically, products are vertically differentiated if, at identical prices, all consumers can agree which they prefer, and variety persists in equilibrium only because consumers find they can afford different levels of quality. Products are horizontally differentiated, in contrast, when different consumers would make different choices even in the absence of any difference in price-some like

$9 \quad$ Estimate based on BARB viewing figures from September-October 2005. 
classical music, some prefer rock. The impact of technical changes such as digitisation on market concentration will depend importantly on the relative significance of these two types of differentiation in broadcast programmes. In the presence of vertical differentiation, cost reductions create a strong tendency towards market concentration to the extent that they enable sellers to produce at higher quality without a significant increase in price. But in the presence of horizontal differentiation, cost reductions allow new entrants into the market to offer services that more closely match the preferences of particular niches of viewers. The latter is the conclusion of the well-known model of Steven Salop (1979), for instance.

A third important feature of broadcasting markets that is not adequately captured by the Rosen model is that quality is not just a matter of talent. As we discussed in section 2, it is also a matter of investment—of the amount that producers spend. ${ }^{10}$ They may spend to improve programme quality partly by paying directly for more attractive content (better writers and actors, or broadcast rights to more popular films and sporting events), and partly by investing in expensive techniques such as special effects, location shooting, larger networks of correspondents for news-gathering, and so on. The important thing about such investments is that they typically add to the fixed costs of programme-making, and so are more attractive the larger the audience the programme can expect to attract. For this reason, reductions in the cost of reaching additional viewers that increase potential audience size — such as when more people take up cable or broadband —may thereby lead to increases in endogenous fixed costs, thus increasing market concentration (or causing it to fall by less than might otherwise be expected). Furthermore, this may be true even in the presence of horizontal differentiation, thereby complicating the effects shown in the Salop model.

In order to compare the effects of vertical and horizontal differentiation, and of the endogenous character of product quality due to investment in programming, we present in the Appendix an extension of Salop's model. This allows for both vertical and horizontal product differentiation, and allows the vertical dimension to depend endogenously on investment. The equilibrium number of firms in the market is determined by a free-entry (zero-profit) condition, on the assumption that firms position themselves at equal intervals around a unit circle representing the ideal preferences of viewers for horizontally-differentiated programme types. The "distance" of a consumer from any given producer can be interpreted as how different is the type of programme

10 In the Rosen model, quality is also strictly speaking endogenous in the sense that it depends on the extent of external diseconomies. However, it does not depend on investment - it is just a function of talent and demand. 
broadcast from the type that the viewer would ideally prefer: this distance imposes a reduction in utility that behaves analytically just like a transport cost.

In this model, we show that reductions in costs of programme-making have an ambiguous effect on the number of firms in equilibrium, and hence on variety, depending on whether they take the form of reductions in the exogenous fixed cost per programme or in the cost of investments in programme quality. The former tend to increase the number of firms (lower fixed costs raise the number of firms who can enter and still make non-negative profits), while the latter tend to lower the number of firms (since firms invest more in raising quality and therefore spend higher fixed costs overall). It is important to note, though, that variety and quality are inversely related in equilibrium: when variety increases, average quality declines, and vice versa.

Furthermore, in this model reductions in variety increase not just quality but the overall utility of both average consumers and marginal consumers (the latter being those furthest away in tastes from what is provided by firms and therefore most likely to lose out from reduced variety). ${ }^{11}$ The reason is that increases in quality not only benefit consumers directly but also indirectly, as a fall in the number of firms reduces the extent of duplication of fixed costs-and competition ensures that these cost savings are passed on to consumers, thereby benefiting them by more than the decline in variety has harmed them (although prices nonetheless rise overall, reflecting higher quality). This conclusion is important as it suggests that some of the suspicion with which digitisation is viewed may be misplaced: reductions in variety, if they occur, may be an important means by which quality improvements take place to the benefit of viewers. Conversely, high levels of variety can sometimes coexist with poor quality of individual programmes. ${ }^{12}$

What about the effect on content rents? With its variable quality, programme content contributes to the vertical differentiation element in the model: greater expenditure on quality translates into higher content rents, as the return to talent is bid up. ${ }^{13}$ Once again this effect depends on the source of the cost savings. Reductions in the fixed costs of programme-making reduce expenditure, and hence rents, but reductions in the cost of

11 This result is a consequence of the excess entry property, which is found here as in the Salop model. Other models of horizontal differentiation, such as Dixit and Stiglitz (1977), have ambiguous results.

12 Those nostalgic for the supposed former glories of public service broadcasting bodies such as the BBC often overlook how poor, by contemporary standards, was the quality of much of the day-to-day programme-making (sceptics might like to consider viewing some of the very first episodes of that science fiction classic "Dr. Who", to say nothing of run-of-the-mill situation comedies and quiz programmes from the 1950s and early 1960s). It is not appropriate to compare the average quality of contemporary programming with only the best of the past.

13 The model simplifies vertical differentiation into a single term. In reality quality has many dimensions, and outcomes may differ depending how digitisation affects the cost of each element. This extension is left for further research. 
making quality improvements increase them. Under the latter circumstances, programme prices are higher, though this reflects quality improvements: consumers (of all tastes) are better off overall.

We also explore the effect of reductions in the transport cost of horizontal differentiation - the cost to consumers of having to consume varieties that do not perfectly match their own preferences. Such reduced costs might come from two sources. First, they might represent intrinsic shifts in preferences that occur, typically as a by-product of habituation (itself a product of trade and globalisation), as consumers who initially find a type of broadcast culturally unfamiliar come to familiarise themselves with it and to enjoy it more. Secondly, they may result from reduced costs to producers of adapting their broadcasts to match the preferences of certain groups of consumers-for instance, by dubbing or subtitling movies, or making versions of situation comedies for foreign audiences using local actors. What the model shows is that reductions in these costs have qualitatively the same impact as a reduction in the cost of improving quality: this reduces the equilibrium number of firms while raising quality, prices and viewer utility.

It is worth noting also that different types of programme have different intrinsic transport costs: action movies, for instance, appeal more easily across cultural and linguistic boundaries than do those that depend on subtleties of social and linguistic observation. This fact has been used to account for the strong dominance of Hollywood movies in world markets, as well as for the fact that the leading challenger to Hollywood's dominance, at least in terms of sheer audience numbers, is the Indian film industry. Tyler Cowen cites a Bombay movie producer, Romu Sippy, on the reasons why India produces mostly action movies:

"Mythological films are not popular, because they offend the Muslim people. Regional films are okay, but they cannot appeal to people who do not speak the language. If you make a dacoit [bandit] movie, you miss out on the south, where they don't have dacoits. Westernized movies may be popular among the educated people of the cities, but what about the rickshaw wallah, the small vendor, the villager? If you get an adult certificate you miss out on the young audience. If you make a good clean film, it may be well received by the critics but commercially it will do nothing. Even a little sex is likely to offend the orthodox Hindu in Uttar Pradesh who goes to see a film first to find out if it is suitable for his daughters. The only thing that all people can relate to and understand is action". 14

14 Cited in Tyler Cowen, Creative Destruction: How Globalization is Changing the World's Cultures, Princeton University Press, 2002. 
Our model has clear findings, therefore, but it has significant limitations too, though these are not the same as those of the Rosen model. First, and most obviously, we do not incorporate differences in talent, so the question of changing rents to talent does not arise. Indeed, the framework of the Salop model has the important limitation that firms are symmetric: they all use the same technology and in equilibrium they are all the same size and charge the same price. Incorporating the insights of the Salop and Rosen models into a single encompassing framework has not to our knowledge been achieved to date, and remains an important task for further research.

Secondly, our model ignores the distinction between the number of firms and the number of programme types. Indeed, we simply equate the two, meaning that each programme type is produced by just one producer. This may be a disadvantage in portraying a world in which there may exist multiple studios producing rather similar types of content; once again, an adequate model of such a process awaits further research.

Finally, we assume that viewers pay for individual programmes, ignoring the fact that programmes are typically bundled into channels, and channels sold together in larger packages. To the extent that channels bundle together a variety of types of content, and different channels do so to different degrees (some channels being very specialised, while others incorporating substantial variety in programme types), this is a significant limitation. As traditional modes of broadcasting are replaced by video streaming over the internet, however, our model might be more suitable. We discuss some issues to do with bundling in section 4 , but note again that a proper model of broadcasting market interactions that incorporates this distinction has yet to be undertaken.

In practice, and with all respect for these limitations of the available models, what kinds of change do we expect to predominate in broadcasting markets? The effect of falling reproduction and transmission costs seems likely to lead to market consolidation, and possibly to the emergence of rents to certain kinds of premium content, while probably encouraging an increase in overall variety of content types available. The result is likely to be more niche programmes, with a smaller audience share for each, and an increasing dominance of a minority of "superstar" content that gains very large audience sharesi.e. greater skewness of returns to talent.

However, these changes will probably be tempered by simultaneous technological developments that have increased both the number of platforms (terrestrial broadcasting, cable, satellite, broadband) and the number of channels within each platform. These relax the constraint of spectrum scarcity, make it cheaper to enter the market, and fragmenting the available audience. As we noted above, this problem already concerns advertisers, who struggle to gain audience attention, and it will increasing preoccupy superstars and 
would-be superstars as well. In effect, it underlines that there is more to gaining an audience than transmission and reproduction costs of programming; gaining attention requires increasing amounts of ingenuity and novelty. If audiences fragment there is likely to be less investment in quality and the return to premium content may fall. On the other hand, if the cost of investing in quality is itself reduced by digitisation, this effect may be mitigated or even reversed.

Another possible countervailing factor may be the presence of network externalities in viewer preferences. It has long been a commonplace that stardom in the film and musical world is driven to an extent by social network effects-individuals have a preference for viewing and listening to those who are already popular with others, either out of simple conformism or because this aids social interaction. (The latter is known as the "water cooler" effect, since it appeals to the fact that stars provide a topic of conversation when individuals meet together). Broadcasting has traditionally played an important role by making it common knowledge what programmes or stars are likely to have been watched by others. It remains to be seen whether these network effects will survive an era of channel proliferation.

It remains to be emphasised, though, that content is not homogeneous. Different programme types have different features, including the nature of their costs of production and the strength of associated network effects. It seems likely, therefore, that there will be a wide range of outcomes - more "niche" content, and more premium content too - lower rents for most producers of content, but lower costs of production too, and the possibility of a very lucrative stardom for a fortunate few. A further point to be stressed is that few conclusions can be drawn from current observations: being in a period of transition between analogue and digital, it is unlikely we are currently observing an equilibrium outcome. For example, high returns to certain types of programming might be a temporary phenomenon, to be eroded in the future by entry and audience fragmentation, or could be a lasting feature of the market. At this stage predictions are highly speculative.

What does all this imply for competition in broadcasting? What are the implications for competition policy?

\section{Challenges for competition policy}

This section discusses challenges facing competition authorities and regulators as the broadcasting industry is reshaped by technological change. We consider a number of propositions, assessing their validity and drawing out implications for policy. 


\section{Content rights replace transmission bottlenecks as sources of market power}

The introduction to this chapter raised two hypotheses concerning market power in the broadcasting industry:

- first, that the falling cost of reproducing and transmitting information has greatly reduced entry barriers, lessening market power; and

- secondly, that rents increasingly come from control of scarce content, rather than from control over means of transmission.

Starting with the first hypothesis, the enormous expansion in transmission capacity and the rollout of multiple broadcasting platforms have relaxed transmission bottlenecks. With plentiful capacity, there is little reason for this to be concentrated in the hands of just a few broadcasters. Nonetheless, concern remains that control over certain key assets might confer market power over broadcasting platforms: terrestrial transmission sites, ${ }^{15}$ satellite conditional access services ${ }^{16}$ and electronic programme guide (EPG) listings. ${ }^{17}$ These assets display economies of scale and are expensive to duplicate (often prohibitively so), akin to essential facilities. Regulators appear concerned that platform operators may exploit control over these assets by raising prices to (other) channel operators or excluding them entirely. Thus, concern over transmission bottlenecks has not fallen away; merely, their location has shifted from transmission capacity itself to related areas.

In expressing these concerns, regulators tend to consider each platform on its own, regarding control over a single platform as conferring dominance in a distinct economic market. This approach may become more questionable in the future as uptake grows and households become familiar with multiple platforms. In time, these trends may result in platform convergence, with different transmission methods forming part of the same economic market. The precise extent of substitution between platforms is a matter for empirical investigation, and further evidence is needed on this point before firm conclusions can be drawn. However, inter-platform competition-if and when this develops sufficiently-lessens concerns on the viewer side of the market and provides

15 The UK communications regulator Ofcom found Significant Market Power (SMP) arising from the site and mast networks of terrestrial transmission operators and imposed access requirements.

16 Oftel (the former UK telecoms regulator, now merged into Ofcom) imposed a "fair, reasonable and non-discriminatory" (FRND) condition on the pricing of technical services (including conditional access) by SSSL, a subsidiary of BSkyB; Ofcom (which replaced Oftel in 2003) is currently considering more stringent price regulation. Regulated platform access was among the remedies imposed in the merger of Italian satellite operators Stream and Telepiù to create Sky Italia, approved by the European Commission in 2003.

17 EPG listing arrangements have been the subject of several disputes, with independent channels arguing for greater prominence. 
strong incentives for platform owners to bring attractive content on board, constraining incentives to restrict access. In view of this, access regulation might no longer be required and competition authorities might adopt a more relaxed approach to intra-platform mergers than has historically been the case. ${ }^{18}$

Broadcasting is a two-sided market, and both sides need to be considered by competition authorities. Although viewers may in future benefit from inter-platform competition, it does not necessarily follow that the other side of the market-e.g. advertisers seeking access to audiences - cannot be exploited. If each viewer joins just a single platform then each platform holds a monopoly over access to its subscribers, thus gaining a degree of market power vis-à-vis advertisers and programme makers. ${ }^{19}$ It should be noted that such a monopoly does not necessarily benefit platform owners: the result will be fiercer competition for viewers - the eyeballs that generate advertising profits-and it is viewers, not platforms, that gain rents. Although this situation may be desirable from the perspective of viewers, it is unlikely to achieve allocative efficiency. When there is multihoming - each viewer joining several platforms - the monopoly problem is mitigated; this outcome may become more prevalent as viewers become accustomed to multiple platforms. Nonetheless, conditions on each side of the market, and interactions between them, must be carefully assessed before any conclusion is reached.

We now turn to the second hypothesis, that rents in broadcasting increasingly come from control of scarce content, with this becoming the new source of monopoly power. High returns to premium content rights might suggest market power, but the discussion of section 3 would query whether this is a permanent phenomenon. Depending on the precise nature of cost savings from digitisation, competition in programme production may either become more intense or may fall, and returns to talent may become more or less skewed. The long-run outcome of these changes is unpredictable, and observations at an intermediate stage may be misleading. Although control over live top-flight football matches has been an important part of the development of pay-TV in several countries, with high revenues being generated for broadcasters and football clubs, market power conferred by these rights may be weaker in the future.

18 The merger of the Italian satellite broadcasters, Stream and Telepiù, was permitted only in view of the enormous losses being incurred by both operators and the likelihood that one would imminently exit, and even then was subject to a wide-ranging set of undertakings. In Germany, where cable is the major means of transmission, the Bundeskartellamt prohibited the acquisition by Kabel Deutschland (KDG) of three other regional cable operators, Ish, Iesy and Kabel Baden-Württemberg (KBW), in 2004; although it subsequently permitted the proposed merger of (the smaller operators) Ish and Iesy in 2005.

19 A similar issue concerns the "competitive bottleneck" in call termination on telephone networks: even with strong retail competition, each network controls access to its own subscribers for incoming callers. 


\section{Viewer markets replace advertiser markets}

In analogue free-to-air broadcasting, economic markets are typically defined in relation to advertisers - the paying customers - not viewers. ${ }^{20}$ Advertising-funded broadcasting is one example of what economists describe as a two-sided market. A broadcaster shows attractive programmes to build an audience; access to this audience is sold to advertisers, thus generating the revenues out of which broadcasts are funded. The two sides of the market - viewers and advertisers - are interdependent and the broadcaster must get both sides on board. These network effects complicate the estimation of demand elasticities and market definition is not straightforward (for such an analysis of printed media see the chapter by Argentesi and Ivaldi in this volume). Moreover, regulation of one aspect must take into account effects on the other (e.g. advertising restrictions affect the quality of programming offered to viewers, an effect emphasised in the chapter by Simon Anderson in this volume).

With the growth of pay-TV, competition must be assessed in relation to subscribers as well as, or even instead of, ${ }^{21}$ advertisers. Substitutes are very different for the two groups: in place of one programme or channel, an advertiser would switch to any other (perhaps a combination) that delivers an audience of a similar size; but this need not consist of the same individuals. Thus, to an advertiser, popular soaps and comedies would substitute for a football match. From the viewer's perspective, however, these programmes are unlikely to be close substitutes: notably, premium programming such as live football matches and Hollywood movies appear to form narrow product markets. ${ }^{22}$ Furthermore, substitutes outside television also differ: while an advertiser might instead advertise on a billboard or in newspapers, a television viewer would seek alternative entertainment, perhaps going to a pub or reading a book.

In advertising-funded broadcasting, network effects resulting from the two-sided nature of the market are important. If advertising declines, such concerns may fall away-only to be replaced in a viewer-driven market by social network externalities. As noted in section 3, individuals benefit from the social interactions that are made possible when they watch the same programmes and can discuss them "around the water cooler". Even

20 For example, in the UK Competition Commission's 2003 inquiry into the merger of two free-to-air terrestrial broadcasters, Carlton Communications and Granada, the analysis focused primarily on the impact on advertisers.

21 As PVRs become widespread, avoidance behaviour may eliminate advertising altogether.

22 In its investigation of the UK satellite broadcaster BSkyB in 2002, the Office of Fair Trading defined premium sports and movie channels as distinct product markets, separate from other programming. See Decision of the Director General of Fair Trading, BSkyB investigation: alleged infringement of the Chapter II prohibition, 17 December 2002. 
in a world of channel proliferation network effects may permit some programmes to retain a large audience share and gain a higher return.

\section{Exclusivity over premium content may be anti-competitive}

In a viewer-defined broadcasting market, programming with particular appeal to viewers and few, if any, substitutes forms a narrow product market which is extremely valuable to broadcasters. Live top-flight football matches might form such a class: fans are willing to pay large sums to watch live matches and regard other sports, and even lower football leagues, as poor substitutes. Competition authorities have in recent years expressed great concern over the sale of premium content rights on an exclusive basis. ${ }^{23}$ With the value of a monopoly exceeding the sum of oligopoly profits, broadcasters will be willing to pay a premium for exclusivity, making this attractive to the seller. ${ }^{24}$ Even when rights are sold as several packages so that multiple winners are possible, these may nonetheless be bought by a single bidder.

Complementarities are important in broadcasting. When programmes form part of a series, such as a soap or sporting championship, watching one episode or event raises the attraction of watching the next. Values are raised when the programmes are offered and consumed together, generating super-additivity. ${ }^{25}$ Even when values are merely additive, bundling-of programmes into channels and of channels into packages-is more profitable than supply on a stand-alone basis, generating economies of aggregation. ${ }^{26}$ For these reasons, broadcasters are typically willing to pay more for combinations of rights than the sum of their stand-alone values: thus, a premium may be offered for multiple or exclusive holdings. Such bidding tends to result in more concentrated holdings-in the limit, full exclusivity.

\section{[INSERT BOX 1 HERE]}

The challenge for competition authorities is that combinatorial bidding may reflect either intrinsic complementarities or market power. If exclusivity maximises viewer surplus or allows pricing efficiencies to be realised, it is socially as well as privately beneficial. But

23 The UK Office of Fair Trading (OFT) challenged collective selling of football rights by the Premier League but lost this case at the Restrictive Practices Court in 1999. Under pressure from the European Commission, the League agreed to offer the rights as several packages so that there might be multiple winners, but successive auctions in 2000 and 2003 ended with all live packages being acquired by BSkyB. At the time of writing the European Commission is negotiating with the Premier League to ensure that there will be more than one winner of the 2006 auction, for contracts from 2007.

24 Armstrong (1999b) discusses private and social incentive for signing exclusive contracts.

25 Super-additivity entails that the combined value of two goods exceeds the sum of their individual values.

26 Bakos and Brynjolfsson (2000) discuss the role of bundling in creating economies of aggregation for information goods, such as those distributed on the internet, and assess their competitive implications. 
these values are difficult to quantify. If such bidding reflects the higher value of a monopoly, on the other hand, a concentrated outcome is detrimental to consumers. With true motivations being hidden from the competition authority the two are observationally equivalent, making policy difficult to formulate.

\section{Exclusionary behaviour is difficult to identify}

Like other information industries, broadcasting has a distinctive cost function. Fixed costs — of programme production, transmission, encryption and reception-are high, but once a programme has been made and broadcast the cost of supplying an additional viewer is zero. Although revenues must of course be raised in some way, any price above zero is profitable at the margin.

This characteristic makes exclusionary behaviour difficult to identify and prosecute. The Areeda-Turner test ${ }^{27}$ states that a price below marginal cost is exclusionary, while prices above this level are permissible. In broadcasting, this rule carries no weight at all. Yet by charging very low prices for additional channels within a bundled pricing scheme, a multi-channel broadcaster may exclude a single-channel competitor (this firm being unable to match the incremental price and operate profitably) while still recouping its own costs overall. The likely outcome is that competition in pay-TV will primarily be between multi-channel operators which compete in offering attractive bundles of channels to subscribers, with competition constraining average prices so that excess profits are curtailed.

\section{Bundling is essential to broadcasting}

Although in some contexts competition authorities are intrinsically suspicious of bundling - the sale of two products for a single price lower than the price at which the products may be purchased separately, if they are available separately at all—in broadcasting markets bundling is inescapable. Indeed, bundling is the source of much of the value added produced in the sector: different scenes are bundled in one programme; different programmes are bundled in one series, different series are bundled in one channel, and different channels are bundled in one subscription. The reasons that may lead broadcasters to bundle content in this way are many and various, and some have a clearer role in creating value than others.

For instance, the broadcaster may put together material for reasons associated with artistic or thematic creativity. The sequence of scenes in a drama, of episodes in a series, or matches in a tournament may aim at creating suspense, attachment to characters or situations, an interesting degree of variety, a growing familiarity on the part of the viewer

27 Areeda and Turner (1975). 
with the material (such as the setting of a drama or the characteristics of a sporting tournament), or simply aesthetic unity in a complex story. This kind of bundling creates value added from complementarity, and typically presupposes that viewers watch all the bundled material. Another possibility is that the types of content bundled together are alternatives, and are therefore substitutes rather than complements - much as a chef will bundle together meals in a menu to create an interesting and varied selection for the diner. Moreover, with a huge quantity of programmes competing for viewer attention, a trusted broadcaster plays an important role in making an initial selection out of which the viewer may then choose. This reduces search costs for the viewer, as well as the cost of making mistakes (which are not the same thing). Such benefits may arise either from the reputation of the broadcaster (which, for familiar reasons, tends to display scale economies), or from the presence of positively correlated preferences for the elements of the bundled material.

There is some uncertainty as to what the impact of digitisation is likely to be on the extent of bundling in the broadcasting sector. Lower filming and editing costs increase the volume and range of programme content from which broadcasters may select in creating their channel output. Meanwhile, greater transmission capacity increases the amount of programming that they are able to distribute to viewers. In one sense this may strengthen the role of broadcasters in selecting and packaging material to make it attractive and accessible to viewers, for example as themed channels. The need for efficient means of revenue generation, which channel bundling tends to be, could heighten this role. However, other developments would seem to reduce the need for broadcasters to act as intermediaries between programme creators and viewers. Producers can make their outputs directly accessible to viewers, for example by posting them on websites, while viewers can use search engines to find programmes of interest and make their selections

Two distinct issues arise in considering the competition impact of such bundling. First there is the question of selection: a broadcaster chooses what material to include in the bundle, which implies choosing not to include certain potential alternative material. Selection is both desirable and inescapable, and indeed is one of the principal ways in which broadcasters exercise their judgement and creativity for the benefit of viewers. However, selection entails refusing to carry other content. Imagine if every broadcaster of films were obliged to allow viewers to choose among alternative competing endings for the films supplied by rival film-makers, and every series to allow viewers to choose among competing episodes at each stage. More bizarrely still, imagine if every news programme were obliged to allow viewers to choose between rival news stories filed by competing correspondents - the very suggestion highlights the fact that selecting news 
and enforcing the quality and reliability of reporting is one of the central functions of news organisations.

The issue of selection extends beyond the choice of film endings and the composition of news bulletins. The selection of programmes to form a channel, whether this is varied or themed, and the combination of channels into a bundle that appeals to a large number of subscribers, are important parts of a broadcaster's role. As a channel packager, the broadcaster must exercise creative and commercial judgement to decide which programmes and channels to include in its offering. Although anti-competitive motives might sometimes be present, it is almost impossible to regulate vertical relations between broadcasters and content providers in such a way as to rule out the possibility of exclusionary foreclosure. Such foreclosure may happen, but no realistic rules could prevent it from happening without stifling quality and creativity in broadcasting. Indeed, it is doubtful that workable rules could even be specified. Obliging platforms owners to grant equal access to (other) broadcasters is a policy that sometimes made sense when platforms were the bottleneck in broadcasting. But it is neither practical nor realistic to impose analogous obligations on channel packagers, giving equivalent rights to independent producers and channels, now that it is bundles of content that increasingly represent scarce assets in the industry.

The second issue is pricing. As Mark Armstrong and Helen Weeds emphasise in their chapter in this volume, bundling implies charging a low or even zero price for additional components of a bundle to a viewer who is already consuming the rest of the bundle. This can be efficient, though it need not always be so, and even when efficient is likely to make it difficult for new channels to enter the market (and may even create a tendency towards natural monopoly or oligopoly). At any rate, without detailed knowledge of viewer preferences of the kind that is typically unavailable to competition authorities, there is no way to formulate rules that adequately track the difference between efficient and exclusionary bundling practices. ${ }^{28}$ The best that can be hoped for is that in certain circumstances where complementarities between components are widespread (as between some components of transmission rights for sporting events, as in the TPS/Canal+ case discussed in Box 1), competition authorities will adopt an approach that is more favourable to bundles that embody these natural complementarities than to those that deny them. In other words, the presence of plausible natural complementarities of viewer

28 In its Competition Act investigation of BSkyB in 2002, the UK's Office of Fair Trading applied an "incremental price" test which compared the incremental price of an additional channel in a bundled pricing scheme to its incremental cost of supply, regarding an incremental price below incremental cost as anti-competitive. This approach is not entirely robust, however, as it ignores additional revenues from new subscribers who are brought into the market by the larger bundle, not merely upgrading from the smaller one. 
preference should be considered a sufficient defence against suspicion of exclusionary intent.

To summarise, bundling is ubiquitous and in many circumstances entirely desirable. Elements of market power that arise through ownership of scarce physical assets (such as broadcasting platforms) may indeed provide an argument for regulatory intervention, for example to ensure access to third parties. But it is likely that physical assets will become less scarce over time through digitisation, while scarcities deriving from the ownership of content assets are much less susceptible to interventions of this kind. The easiest cases to deal with may be in acquisitions markets, where mergers (for example) may be motivated purely by the wish to establish a monopoly over certain kinds of content. A restrictive attitude to mergers of this kind will be just as warranted as for mergers where more traditional, physical assets are at stake. But competition authorities need to be careful not to adopt overly restrictive attitudes to other industry practices, such as bundling (or other forms of non-linear pricing), that may have a pro-competitive rationale in terms of either the creativity of the broadcasting sector, or its role in providing trusted content for viewers in an age that is increasingly characterised by information overload rather than information scarcity.

\section{Conclusions}

We conclude with some key messages from this analysis for students, researchers and policymakers.

\section{Lessons for students}

- Technological changes in broadcasting will lead to diminishing scarcity of physical assets (such as transmission platforms), but may increase the scarcity of certain kinds of premium content.

- Lower entry costs mean that overall number of channels and types of programme in the market can increase, broadening diversity of provision, while the audience share (and income) of the leading channels and programmes also increases. Thus niche programming can coexist with an increasing dominance of superstars.

- The ability to raise quality at lower cost, resulting from digitisation, may increase investment in endogenous programme costs, an effect which tends to limit the expansion of channel numbers.

\section{Lessons for researchers}

- We need to understand better the effect of differences in talent among producers in a world in which there is also horizontal differentiation of viewers' tastes. A 
comprehensive model encompassing the Rosen (1981) and Salop (1979) models has yet to be developed.

- We need to develop a better understanding of the circumstances in which bundling can be exclusionary and to develop rules of thumb for recognising such circumstances in practice, especially when possible efficiency and exclusionary motives co-exist.

\section{Lessons for policymakers}

- Scarcity of transmission capacity is diminishing in importance. Combined with competition between platforms, this reduces the need to regulate platform access.

- Viewer markets are likely to grow in importance relative to advertiser markets for competition policy.

- Control over scarce content may be a means of anti-competitive conduct, but aside from concentration of content via mergers, authorities should be wary of adopting a restrictive attitude to practices such as bundling and non-linear pricing, which play an important part in the creation of value in the broadcasting sector.

\section{Appendix: Digitisation and Entry}

In section 2 we described the impact of digitisation in reducing fixed costs of programme provision (such as video storage, editing and transmission), and generating cheaper and more effective ways of raising a programme's appeal to viewers (better special effects, speedier news reporting, etc.). Then, in section 3 , we argued that digitisation might reduce the "transport cost" of horizontal differentiation-the cost to consumers of having to consume varieties that do not perfectly match their own preferences. These changes can be characterised as: (i) a fall in the exogenous fixed cost of programme provision, (ii) a reduction in the cost of raising programme quality, which affects endogenous costs, and (iii) a reduction in the unit transport cost.

The appendix presents a model that combines these features. ${ }^{29}$ The Salop (1979) model of entry into a differentiated product market is augmented by incorporating endogenous programme quality, where higher quality increases viewer surplus and raises programme costs. Using this framework we examine the impact of the three features noted above on the equilibrium number (and hence diversity) of programmes, ${ }^{30}$ programme quality and the prices paid by consumers.

29 This model owes its origin to joint work with Mark Armstrong.

30 We refer to "programmes" throughout: these are best thought of as distinct series or genres (e.g. the soap EastEnders, or FA Premier League football matches) which are differentiated from one another, 


\section{Salop model with endogenous quality}

Viewers (with measure 1) are uniformly distributed around a circle of circumference 1, and incur a per-unit transport cost $t$. Viewer utility (ignoring transport costs) from watching programme $i$ is given by

$$
u_{i}=v_{i}-p_{i}
$$

where $v_{i} \geq 0$ is programme $i$ 's quality, and

$p_{i} \geq 0$ is the price charged for programme $i .^{31}$

Each firm provides a single programme type. Once a programme has been made, the marginal cost of supplying an additional viewer is zero. The cost $C$ of providing a programme of quality $v$ has two elements, an exogenous cost $K$ and an endogenous, quality-related term

$$
C=K+\frac{1}{2} \mathcal{N}^{2}
$$

where $K>0$ is a fixed cost (for a programme of minimal quality), and

$\gamma>0$ is a parameter representing the cost of raising quality.

Firms are located at equal intervals around circle, and entry occurs until it is no longer profitable. Existence of competitive equilibrium with a positive number of firms requires $2 t \gamma>1$; this is assumed henceforth. For the market to be covered the marginal consumer (located equidistant between two firms) must obtain non-negative utility, which requires $3 t \gamma \leq 2$ (this can be seen from expression [9] below). ${ }^{32}$ Together these conditions entail the following parameter restriction

$$
6 t \gamma \in(3,4]
$$

\section{Equilibrium}

Solving the model, the equilibrium number of firms (and hence programme diversity) is given $\mathrm{by}^{33}$

rather than individual programmes that are very similar in content (e.g. a single EastEnders episode or football match).

31 This assumes that the programme is financed from viewer subscription alone. Advertising funding (and the viewer disutility it causes) can be incorporated without altering the results presented here.

32 Alternatively $v_{i}$ could be regarded as the viewer's valuation of quality above some base level $v_{0}$, conferred by the minimum investment $K$, where this is sufficient to ensure participation.

33 Note that taking the limit as $\gamma \rightarrow \infty$ the expression collapses to $N=\sqrt{t / K}$, the usual Salop formula. 


$$
N=\sqrt{\frac{2 t \gamma-1}{2 \gamma K}} .
$$

Equilibrium quality and price, respectively, are given by

$$
v=\frac{1}{\gamma N}
$$

and

$$
p=\frac{t}{N}
$$

\section{Comparative statics}

We can now study the impact of a reduction in (i) the exogenous programme cost, $K$, (ii) the cost of raising quality, $\gamma$, and (iii) the unit cost of transport, $t$.

(i) Exogenous programme cost, $K$

From expression [4], a reduction in $K$ increases the equilibrium number of firms, $N$, increasing diversity; this is the same result as is found in Salop (1979). Greater competition entails a reduction in equilibrium quality per programme, $v$, and a lower equilibrium price, $p$ (from expressions [5] and [6] respectively). This is the "audience fragmentation” effect, whereby greater entry shrinks each programme's audience share and quality falls.

(ii) Cost of raising quality, $\gamma$

From [4], a reduction in $\gamma$ reduces the equilibrium number of firms, lowering diversity. ${ }^{34}$ From [6], the reduction in competition increases equilibrium price, $p$. Equilibrium quality provision increases, both via the direct effect of lower $\gamma$ and indirectly through the reduction in $N$. Substituting for $N$ we can write

$$
v=\sqrt{\frac{2 K}{\gamma(2 t \gamma-1)}} .
$$

It can be seen from this expression that a reduction in $\gamma$ increases equilibrium quality. So: a reduction in the cost of raising quality results in a smaller number of programmes in equilibrium, each of which charges a higher price and provides higher quality. Note that higher quality raises endogenous programme costs, increasing $C$.

\footnotetext{
${ }^{34}$ As long as the existence condition $2 t \gamma>1$ continues to hold.
} 
(iii) Unit transport cost, $t$

From [4], a reduction in $t$ reduces the number of firms, $N$, and therefore (from [5]) raises quality, $v$. Its impact on price is ambiguous since it lowers both the numerator and the denominator of [6]. For parameter values within the range given by [3], however, $p$ is decreasing in $t$, so we can conclude that a reduction in $t$ increases the price. Note that the directions of the comparative static results are the same as those in $\gamma$.

\section{Viewer welfare}

In addition to considering the impact of these changes on the number of firms, we may also be interested in their impact on the welfare of consumers. ${ }^{35}$ Noting that utility of a given consumer is given by the equilibrium quality minus the price and transport cost, we can write

$$
u_{i}=v_{i}-p_{i}-\frac{t}{2 N}
$$

for the utility of the marginal consumer-the one furthest in preferences from the varieties supplied by the firms. This is the consumer with "niche" tastes who is often cited as the most likely to lose out from the homogenisation of market standards brought about by digitisation. The most "mainstream" consumer, on the other hand, is the one whose tastes are precisely equal to the variety supplied by the firm and whose utility is therefore just equal to $u_{i}=v_{i}-p_{i}$. The average consumer therefore has a utility given by the mean of these two types. Substituting equations [5] and [6] we can therefore write

$$
\bar{u}=(4-5 t \gamma) \sqrt{\frac{K}{8 \gamma(2 \gamma t-1)}}
$$

for the utility of the average consumer and

$$
u^{\prime}=(2-3 t \gamma) \sqrt{\frac{K}{2 \gamma(2 \gamma-1)}}
$$

for the utility of the marginal consumer.

The Salop (1979) model exhibits excess entry, and a similar result is found in this model. Thus, any change in parameter values that reduces the number of firms increases utility, with both average and marginal utility displaying the same qualitative responses. A

35 Note that welfare outcomes are identical to consumer outcomes since, with free entry, profit always equals zero. 
reduction in $K$ reduces the utility of both marginal and average consumers, because the increase in the number of firms reduces quality by more than it reduces prices and (marginal or average) transport costs. However, a reduction in either $\gamma$ or $t$ increases utility, because the reduction in the number of firms gives them an incentive to invest in higher quality that more than offsets the increase in price and (marginal or average) transport costs. $^{36}$

Comparative static results for the key variable are summarised in the following table.

\section{Table 3.1: Comparative statics}

\begin{tabular}{c|cccc}
\hline & \multicolumn{5}{|c}{ Equilibrium outcome } \\
Variable & $N$ & $v$ & $p$ & $u$ \\
\hline$K$ & - & + & + & + \\
$\gamma$ & + & - & - & - \\
$t$ & + & - & - & - \\
\hline
\end{tabular}

\section{The impact of digitisation}

The analysis demonstrates that digitisation may have very different effects according to the precise mechanism through which it works: a fall in exogenous programme costs and a fall in the cost of raising quality have very different effects, for instance. The impact of digitisation on programme diversity, quality and prices is sensitive to the precise nature and degree of the changes it induces, making it difficult to anticipate.

If digitisation reduces both $K$ and $\gamma,{ }^{37}$ the overall impact depends upon which of the two mechanisms dominates. If the exogenous cost effect is stronger, the numbers of channels increases and price falls, while programme quality may decrease, remain unchanged, or increase. ${ }^{38}$ If the endogenous cost effect dominates, programme numbers fall while both prices and quality increase.

The analysis also demonstrates that a change resulting in a reduction in programme numbers is typically good for viewer welfare, even the welfare of those niche consumers whose preferences are furthest from what the remaining programmes provide. This is because quality improves, and there is less duplication of programme costs—savings that

36 Note that a reduction in $t$ nonetheless increases both average and marginal transport costs (given by $t / 4 N$ and $t / 2 N$ respectively), as the indirect effect via lower $N$ more than offsets the direct effect of lower $t$.

37 Or $t$, which has a similar impact to $\gamma$.

38 There are parameter values for which $N$ increases, yet the combined effect (of higher $N$ and lower $\gamma$ ) results in higher $v$. 
are passed on to viewers through the effect of competition (although prices rise overall due to higher quality provision). However, one caveat should be noted: these welfare results are linked to the excess entry property of equilibrium, which arises in this model as in Salop (1979). The excess entry result is not always present in other models of horizontal differentiation; ${ }^{39}$ thus, it is unclear whether these results would carry over to alternative formulations.

\section{References}

Adams, William, and Janet Yellen (1976). "Commodity bundling and the burden of monopoly”, Quarterly Journal of Economics 90: 475-498.

Areeda, Phillip, and Donald F. Turner (1975). "Predatory Pricing and Related Practices under Section 2 of the Sherman Act”, Harvard Law Review, 88: 697-733.

Armstrong, Mark (1999a). "Price discrimination by a many-product firm”, Review of Economic Studies 66: 151-168.

Armstrong, Mark (1999b). “Competition in the Pay-TV Market”, Journal of the Japanese and International Economies, 13: 257-280.

Bakos, Yannis, and Erik Brynjolfsson (1999). "Bundling information goods: pricing, profits and efficiency”, Management Science 45: 1613-1630.

Bakos, Yannis, and Erik Brynjolfsson (2000). "Bundling and Competition on the Internet: Aggregation Strategies for Information Goods”, Marketing Science 19: 6382.

Dixit, Avinash K., and Joseph E. Stiglitz (1977). "Monopolistic Competition and Optimum Product Diversity”, American Economic Review, 67: 297-308.

Frank, Robert H., and Philip J. Cook (1996). The Winner-Take-All Society: Why the Few at the Top Get So Much More Than the Rest of Us. Penguin, NY/London.

McAfee, Preston, John McMillan and Michael Whinston (1989). "Multiproduct monopoly, commodity bundling, and correlation of values”, Quarterly Journal of Economics 104: 371-384.

Motta, Massimo, and Michele Polo (2003). "Beyond the Spectrum Constraint: Concentration and Entry in the Broadcasting Industry”, chapter 3 in M. Baldassarri and L. Lambertini (eds.), Antitrust, Regulation and Competition. Palgrave MacMillan, New York.

Rosen, Sherwin (1981). “The Economics of Superstars”, American Economic Review, 71: 845-858.

$39 \quad$ E.g. Dixit \& Stiglitz (1977). 
Salop, Steven C. (1979). "Monopolistic Competition with Outside Goods”, Bell Journal of Economics, 10:141-156.

Sutton, John (1991). Sunk Costs and Market Structure. MIT Press, Cambridge/London. 


\section{BOX 1: THE TPS-CANAL+ CASE}

In 2002 the French Football League organised a first-price sealed-bid auction for the transmission rights for matches in the First Division. There were two main participants in the auction: the broadcasters TPS (a subsidiary of the private broadcaster TF1) and Canal+ (a subsidiary of Vivendi Universal). Three main lots were up for auction, and bidders could specify whether they wanted the lots exclusively or non-exclusively, the value of the latter being significantly lower. The lots were:

- The live broadcast to all subscribers of the first-choice match in each week and the third-choice match in each week;

- The live broadcast to all subscribers of the second-choice match in each week and the weekly magazine, consisting of a round-up of all the highlights of the previous week; and

- All matches broadcast on a pay-per-view basis.

In the event TPS submitted bids of $€ 260 \mathrm{~m}$, €238m and €113m for the three lots, with an additional €9m if the second and third lots were on an exclusive basis. Canal+ submitted bids of $€ 150 \mathrm{~m}, € 20 \mathrm{~m}$ and $€ 20 \mathrm{~m}$, plus a large bonus of $€ 290 \mathrm{~m}$ if it could obtain all three lots exclusively (all sums represented annual payments). Canal+ was awarded the contract, but TPS complained that this bid was effectively exclusionary and would drive it out of the pay-TV market altogether. The case was referred to the French Competition Council and after arbitration the parties agreed to annul the auction.

An important feature of the case was that Canal+ had previously enjoyed the rights to the first-choice live broadcast and to the magazine (which it had pioneered). It argued that these two components were strongly complementary, since many football fans derived much greater pleasure from following the league systematically than from watching isolated matches. It further argued that this complementarity (rather than any exclusionary intent) was what justified the large bonus bid for all three lots together.

An interesting question arises if it is true that such complementarities exist (which there is no reason to doubt). For in that case, if the League had divided the lots differently, with the first-choice match and the magazine allocated to the same lot, and the second- and third-choice matches together in a different lot, Canal+ could have bid for the former and TPS for the latter. But the prices would almost certainly have been much lower, since the bidders would have had different target lots and would not have been strongly competing against each other. The result of the auction can be seen as the direct consequence of the League's decision to divide up the rights among lots in such a way as to set the bidders competing fiercely against each other. There is no reason to think that the League was unaware of the consequences of its method of dividing the lots, innocent as it may have looked at the time.... 